DOI: $10.4274 /$ jarem.galenos.2020.2900

J Acad Res Med 2020;10(2):195-9

\title{
Cases with Gastrointestinal System Findings and Diagnosed with Malignancy Outside the Gastrointestinal System; Case Series
}

\author{
(1) Nafiye Urgancı1', (1) Reyhan Gümüştekin2, (1) Bahar Genç3, (1) Z. Yıldız Yıldırmak4 \\ 1 University of Health Sciences Turkey, Şişli Hamidiye Etfal Training and Research Hospital, Clinic of Pediatric Gastroenterology, İstanbul, Turkey \\ 2 University of Health Sciences Turkey, Şişli Hamidiye Etfal Training and Research Hospital, Clinic of Child Health and Diseases, İstanbul, Turkey \\ 3University of Health Sciences Turkey, Şişli Hamidiye Etfal Training and Research Hospital, Clinic of Pediatric Oncology, İstanbul, Turkey \\ ${ }^{4}$ University of Health Sciences Turkey, Şişli Hamidiye Etfal Training and Research Hospital, Clinic of Pediatric Hematology and Oncology, \\ İstanbul, Turkey
}

Cite this article as: Urgancı N, Gümüştekin R, Genç B, Yıldız Yıldırmak Z. Cases with Gastrointestinal System Findings and Diagnosed with Malignancy Outside the Gastrointestinal System; Case Series. J Acad Res Med 2020;10(2):195-9

\begin{abstract}
In these case series, patients admitted to pediatric gastroenterology outpatient clinic with gastrointestinal complaints in the last year and diagnosed with malignancy after the examinations were discussed. Nine patients diagnosed with malignancy were evaluated with biochemical, imaging and histopathological methods. One of the patients, aged 4 months 8 years, was diagnosed with Burkitt's leukemia, two were diagnosed with Burkitt's lymphoma, the other two were diagnosed with neuroblastoma while two were diagnosed with posterior fossa tumor, two were diagnosed with Langerhans cell histiocytosis. All patients were referred to the pediatric oncology service for further treatment. We think that patients presenting with gastrointestinal findings should be evaluated in more detail by general pediatricians before they are referred to minor outpatient clinics.
\end{abstract}

Keywords: Non-gastrointestinal system, malignancy, childhood

\section{INTRODUCTION}

Vomiting, abdominal distention, abdominal pain and weight loss are common symptoms and signs that are common in pediatric practice. These general signs and symptoms are frequently followed with different diagnoses. However, the fact that these symptoms are long-lasting, insistent, and multiple and coexisting should bring to mind the neoplastic diseases in differential diagnosis. Abdominal bloating may be due to diffuse growth of intra-abdominal organs or it may be handled as a separate tumor. The palpated mass may be due to a simple cause such as fechaloma, as well as gastrointestinal system anomalies, cysts, inflammatory diseases or benign neoplasms. Depending on the location of the mass, there may be symptoms such as constipation and vomiting. The mass can often be noticed by the family in the form of swelling, stiffness, or asymmetry in the abdomen while the child is being dressed or bathing. But masses inside the abdomen, especially those in the retroperitoneal region, often escape the attention of the child's family until they reach large sizes $(1,2)$. Another rare, sometimes life-threatening disease is Langerhans cell histiocytosis, which is caused by skin lesions. This disease can often be treated as a cow's milk allergy, especially due to rashes in the body and clinical signs such as diaper dermatitis $(3,4)$. For differential diagnosis, good anamnesis, good systemic physical examination, laboratory and imaging support are required.

In this article, patients who were referred from general pediatric polyclinics to pediatric gastroenterology polyclinics for further examination and treatment with gastrointestinal system symptoms

ORCID IDs of the authors: N.U. 0000-0003-4854-507X; R.G. 0000-0001-5813-4448; B.G. 0000-0002-5237-8377; Z.Y.Y. 0000-0003-3939-2761. 
and who were diagnosed with malignancy after examinations are discussed.

\section{CASE PRESENTATION}

\section{Case 1}

A 3-year-old male patient was brought to the pediatric gastroenterology outpatient clinic with complaints of abdominal bloating and abdominal pain. In his history, it was learned that she had been diagnosed with abdominal pain, anorexia for two months, and not gaining weight since the last one month, despite the outpatient clinic admissions, weight loss increased gradually. On physical examination, the general condition of the case, whose body weight and height was below 3 percentile, was moderate, cachectic and fond-looking, and the eyeballs were collapsed. Respiratory examination was natural. Peak heart rate in the cardiovascular system was $140 / \mathrm{min}$ and rhythmic. A $2 / 6$ severity systolic murmur was detected in the apex. Organomegaly could not be palpated since abdominal distention was excessive. Laboratory investigations were hemoglobin $(\mathrm{Hgb}): 10 \mathrm{gr} / \mathrm{dL}$, hematocrit (Hct): $30 \%$, white blood cell: $8380 / \mathrm{mm}^{3}$, platelet count: $44,000 / \mathrm{mm}^{3}$. Aspartate transaminase (AST): $56 \mathrm{U} / \mathrm{L}$ alanine transaminase (ALT): $9 \mathrm{U} / \mathrm{L}$, gamma-glutamyl transpeptidase (GGT) $20 \mathrm{U} / \mathrm{L}$, alkaline phosphatase (ALP) $79 \mathrm{U} / \mathrm{L}$, total protein $5.4 \mathrm{~g} /$ $\mathrm{dL}$, albumin $2.9 \mathrm{~g} / \mathrm{dL}$, urea $28 \mathrm{mg} / \mathrm{dL}$, creatinine $0.17 \mathrm{mg} / \mathrm{dL}$, iron $40 \mathrm{ng} / \mathrm{dL}$, iron binding capacity $206 \mathrm{ng} / \mathrm{dL}$, ferritin: $21 \mathrm{ng} /$ dL. Immunoglobulin (Ig)A was $36 \mathrm{mg} / \mathrm{dL}$, IgG $686 \mathrm{mg} / \mathrm{dL}$, IgM $49 \mathrm{mg} / \mathrm{dL}$. Atypical cell was not detected in peripheral smear. In abdominal ultrasonography (USG), no pathology other than fechaloma was detected. EMA IgA and EMA IgG examination of the patient who had a hard poop production 3 times a week was negative. Abdominal distension gradually increased and abdominal tomography [computed tomography (CT)] showed dilatation of the bowel loops and an increase in the thickness of the bowel in the right hepatic flexor. Neuron specific enolase (NSE), lactate dehydrogenase (LDH), urine vanillylmandelic acid (VMA) and B human chorionic gonadotropin (HCG) levels were normal for the differential diagnosis of neuroblastoma. A hard mass with uncertain borders was found around the navel. In repeated abdominal USG, hypoechoic nodular areas of $7 \times 6.5 \mathrm{~mm}$ and $7 \times 7.5 \mathrm{~mm}$ in the left lobe in the parenchyma (metastatic areas associated with possible lymphoproliferative process defined in the epigastrium), gathered together in the midline, epigastrium, mass appearance. Thin walled hypoechoic lesions of millimeter sizes were observed in both kidneys, the largest of which was $7 \mathrm{~mm}$ in diameter in the right kidney. Repeated abdominal CT showed increased kidney sizes (metastasis) and a mass in the hepatic flexura in the right colon. In laboratory studies of the case with intermittent fever, alkaline hydration was started with the pre-diagnosis of malignancy on calcium $13.6 \mathrm{mg} / \mathrm{dL}$ and uric acid $7.8 \mathrm{mg} / \mathrm{dL}$. L3-type lymphoblasts containing vacuoles were seen in $40 \%$ of bone marrow aspiration and stoplasmas. Burkitt was diagnosed with leukemia and underwent chemotherapy at a pediatric oncology clinic. Case was excitus caused by sepsis.

\section{Case 2}

A 9-month-old girl was brought with the complaint of abdominal distention since a week. It was learned that there was no history of maternal-parental consanguinity, that she was born as a result of uneventful pregnancy and that there was no feature in the postnatal period. In her physical examination, her weight was $10 \mathrm{~kg}$ (90 per) and her height was $67 \mathrm{~cm}$ (3-10 per). Her general condition was medium, pale and her respiratory and cardiovascular system examinations were normal. The liver of the patient with abdominal distension was to reach the inguinal area and his spleen was palpated $5 \mathrm{~cm}$. Laboratory investigations were $\mathrm{Hgb}: 7.1 \mathrm{gr} / \mathrm{dL}$, Hct: $28 \%$ L/dL, white blood: $3420 / \mathrm{mm}^{3}$, Platelet: $97,000 / \mathrm{mm}^{3}$, AST: 25 U/L, ALT: 30 U/L, GGT: 20 U, ALP: 272 U/L, T protein: $7.5 \mathrm{gr} / \mathrm{dL}$, Albumin: $4.3 \mathrm{gr} / \mathrm{dL}$, urea: $17 \mathrm{mg} / \mathrm{dL}$, creatinine: $0.8 \mathrm{mg} / \mathrm{dL}$, iron: $67 \mathrm{mg} /$ total iron binding capacity: $215 \mathrm{mg} / \mathrm{dL}$, ferritin: $188 \mathrm{mg} / \mathrm{L}$, IgA: 31 mg/dL, IgG: 817 mg/dL, IgM: 45 mg/dl, LDH: 640 IU/L, Uric acid: $8.2 \mathrm{mg} / \mathrm{dL}$ and prothrombin time resulted normally. Hepatitis $\mathrm{A}, \mathrm{B}$ and TORCH panel were negative. Atypical cell was not seen in peripheral smear. In abdominal USG, liver and spleen were large and liver parenchyma was observed homogeneously. Intestinal colon thickening and adjacent mesenteric lymphadenopathies adjacent to the intestine segments causing a mass appearance in the colon in the lower right quadrant of the abdomen were interpreted as a preliminary diagnosis of Burkitt lymphoma. Computerized CT revealed hepatosplenomegaly, paraaortocaval mass and lymphadenopathy. Burkitt lymphoma was diagnosed as a result of examination of laparoscopic biopsy material.

\section{Case 3}

A 3-year-old girl was brought in with a complaint of difficulty breathing. In her story, it was stated that since 15 days of restlessness, abdominal pain and abdominal bloating, she suddenly complained of difficulty in breathing and had difficulty urinating during the day. She was $13 \mathrm{~kg}(25$ per) in weight and 96 $\mathrm{cm}$ (25-50 per) in physical examination. The general condition of the patient was fond, restless, agitated, pale-looking and dyspneic and tachycardic. The presence of organomegaly could not be evaluated because there was an advanced degree of distension in the abdomen. Laboratory examinations were Hgb: $7.6 \mathrm{gr} / \mathrm{dL}$, Hct: $30 \%$, white blood: $12420 / \mathrm{mm}^{3}, \mathrm{PLT}: 70,000 / \mathrm{mm}^{3}$. AST: $28 \mathrm{u} / \mathrm{L}$ ALT: $33 \mathrm{u} / \mathrm{L}, \mathrm{GGT}: 21 \mathrm{U} / \mathrm{L}, \mathrm{ALP}: 172 \mathrm{U} / \mathrm{L}$, T protein: $7.6 \mathrm{~g} / \mathrm{dL}$, Albumin: $4.3 \mathrm{gr} / \mathrm{dL}$, urea: $16 \mathrm{mg} / \mathrm{dL}$, creatinine : 0.6 $\mathrm{mg} / \mathrm{dL}$, iron: $78 \mathrm{mg} / \mathrm{dL}$, total iron binding capacity: $115 \mathrm{mg} / \mathrm{dL}$, ferritin: $128 \mathrm{mg} / \mathrm{L}$, IgA: $32 \mathrm{mg} / \mathrm{dL}$, lgG: $916 \mathrm{mg} / \mathrm{dL}$, IgM: $52 \mathrm{mg} /$ $\mathrm{dL}$, prothrombin time: $88 \%$. LDH $842 \mathrm{IU} / \mathrm{L}$, uric acid: $10.2 \mathrm{mg} / \mathrm{dL}$, hepatitis $A, B$, and TORCH panel were negative. In abdominal USG, liver and spleen were large and liver parenchyma was observed homogeneously. Cells compatible with lymphoblasts were seen in peripheral smear. The patient, who was followed up in the intensive care unit, died on the third day of his hospitalization due to respiratory and renal failure. As a result of the examination of the post-mortem biopsy material, the case was diagnosed with Burkit lymphoma. 


\section{Case 4, 5}

Two 4-month-old female patient applied for bloating in the abdomen for 3 days. It was learned that the patients who had no complaints in their history had previously noticed bloating in the abdomen and had repeatedly applied to a doctor because of their increasing complaints. In their physical exams, one's weight was $7200 \mathrm{~g}$ (90 per) in length $61 \mathrm{~cm}$ (25 per), the other's weight was $7000 \mathrm{~g}(75-90 \mathrm{p})$, height $60 \mathrm{~cm}(25 \mathrm{p})$. The general condition of these cases was moderate, fever $36{ }^{\circ} \mathrm{C}$, respiratory sounds were bilaterally equal, normal and the number of breaths per minute was 35 , cardiovascular system examinations were normal. The liver of patients with abdominal distention was palpable in the inguinal and spleen midclavics and 5-6 cm. In laboratory investigations, Hgb: $11.9 \mathrm{gr} / \mathrm{dL}, \mathrm{Hct}: 30 \%$, white blood: 19,200/mm³, platelet: 219,000/mm³, AST: 25 U/L, ALT: 32 U/L, GGT: 23 U/L, ALP: $201 \mathrm{U} / \mathrm{L}$, T protein: $7.8 \mathrm{~g} / \mathrm{dL}$, albumin: $4.2 \mathrm{gr} / \mathrm{dL}$, urea: $22 \mathrm{mg} / \mathrm{dL}$, creatinine: $0.7 \mathrm{mg} / \mathrm{dL}$, iron: $78 \mathrm{mg} / \mathrm{dL}$, total iron binding capacity: $215 \mathrm{mg} / \mathrm{dL}$, ferritin: 178 mg/L, IgA: 34 mg/dL, IgG: 616 mg/dL, IgM: 42 mg/dL, Prothrombin time $89 \%$ and acid phosphatase: 8.1 were detected. Hepatitis A, B and TORCH panel were negative. Liver, spleen and liver parenchyma were heterogeneous in the abdominal USG of both cases. There were no atypical cells in the bone marrow aspiration examination. The NSE average was 81.4 (high) and VMA >1000 (very high). Gaucher's disease enzyme levels in both cases were also found to be normal. The cases were diagnosed with neuroblastoma as a result of the observation of small blue cells in histopathological investigations of liver biopsies.

\section{Case 6}

A two-year-old baby boy was brought with vomiting after feeding. In his history, it was learned that he had vomited after each feeding since his birth and that there was a slowdown in weight gain. No feature was found in the history and history of the case. On physical examination, the general condition of the patient, whose weight was $11 \mathrm{~kg}$ (25 per) and $84 \mathrm{~cm}$ (25-50 per) in length, was good and active. Respiratory and cardiovascular system of the patient was normal and organomegaly was not detected. Laboratory examinations were $\mathrm{Hgb}$ : $10.6 \mathrm{gr} / \mathrm{dL}$, Hct: $32 \%$, white blood: $7420 / \mathrm{mm}^{3}$, platelet: $370,000 / \mathrm{mm}^{3}$. No characteristics were observed in the abdominal USG of the patient with normal serum electrolytes, liver and renal functions. Anti-reflux treatment was recommended. Although there was no improvement in complaints in the follow-up, there was no characteristic in the fundus oculi examination of the case. However, he was referred to neurosurgery because of mass determination in posterior fossa in computerised brain tomography.

\section{Case 7}

An eight-year-old male patient was brought to the pediatric gastroenterology outpatient clinic with the complaint of vomiting. It has been learned that there have been vomiting attacks, especially in the morning, for six months, gastritis and vomiting treatments have been given in repeated polyclinic applications, but morning vomiting has been increasing since the last few days.
His physical examination revealed a weight of $26 \mathrm{~kg}$ (50 per) and a height of $127 \mathrm{~cm}$ (50 per), and his general condition was moderate, fever $36^{\circ} \mathrm{C}$, and his color was pale. Respiratory examination was normal, peak heart rate: $80 \mathrm{~min} /$ rhythmic, liver and spleen were not palpable. Hb: $12 \mathrm{gr} / \mathrm{dL}$, Hct: 38\%, white blood cell: 7880/mm3, platelet count: 344,000/mm3 . AST: $36 \mathrm{U} / \mathrm{l}, \mathrm{ALT}: 29 \mathrm{U} / \mathrm{l}, \mathrm{GGT}: 21 \mathrm{U} / \mathrm{L}$, ALP: $269 \mathrm{U} / \mathrm{L}$, total protein $6.4 \mathrm{gr} / \mathrm{dL}$, Albumin $3.9 \mathrm{gr} / \mathrm{dL}$, urea $28 \mathrm{mg} / \mathrm{dL}$, creatinine $0.17 \mathrm{mg} / \mathrm{dL}$ were detected. Bilateral papil edema was detected in the fundus oculi examination and cranial CT revealed a mass in the posterior cavity and the patient was referred to neurosurgery.

\section{Case 8}

A nine-month-old girl was brought to our pediatric emergency clinic with complaints of fever, abdominal distention and paleness since two months. In her history, it has been learned that they have been using various antibiotics for recurrent outpatient clinic applications due to intermittent fever and abdominal bloating for five months, but abdominal bloating and paleness have increased since the last few days. In her physical examination; weight was $8000 \mathrm{gr}$ and length was $67 \mathrm{~cm}$ (50 percentile), general condition was medium, fever $38{ }^{\circ} \mathrm{C}$, color was pale. Respiratory examination was normal. The PHR was $120 \mathrm{~min} /$ rhythmic. Systolic murmur at the apex was $1 / 6$. The liver of the patient with abdominal distension was $5 \mathrm{~cm}$ past the edge of the midclavicular line and costa. The spleen was palpated at $4 \mathrm{~cm}$ and medium hardness. Laboratory investigations were $\mathrm{Hgb}: 10 \mathrm{gr} / \mathrm{dL}, \mathrm{Hct}$ : 31\%, leukocyte count: 4380/mm33, platelet count: 144,000/mm3 . AST: $56 \mathrm{U} / \mathrm{L}, \mathrm{ALT}: 49 \mathrm{U} / \mathrm{L}$, GGT $20 \mathrm{U} / \mathrm{L}$, ALP: $279 \mathrm{U} / \mathrm{L}$, total protein: $5.4 \mathrm{gr} / \mathrm{dL}$, albumin: 2.9 gr/dL, urea: $28 \mathrm{mg} / \mathrm{dL}$, creatinine: $0.17 \mathrm{mg} / \mathrm{dL}$, iron: $30 \mathrm{ng} / \mathrm{dL}$, iron binding capacity $406 \mathrm{ng} / \mathrm{dL}$, ferritin: $10 \mathrm{ng} / \mathrm{dL}$, vitamin B12: 189 pg/mL, folic acid: $7 \mathrm{ng} / \mathrm{mL}$, IgA 208 mg/dL, lgG: 686 mg/dL, IgM It was $49 \mathrm{mg} / \mathrm{dL}$. Alpha fetoprotein, NSE, fibrinogen levels were normal. Microcytic anemia was detected in its peripheral spread. Hepatosplenomegaly was present in the abdominal USG and parenchyma was homogenous. The case with pancytopenia and fever was treated with antibiotics. In addition, Cytomegalovirus, Epstein-Barr virus, Parvovirus IgM, hepatitis A, B and C panel were found to be negative. Microcytic anemia was present in the bone marrow aspiration examination, hemophagocytosis and atypical cells were not found. In addition to anaemia, tachypnea, tachycardia, cardiac failure and $40 \%$ prothrombin activity, the patient was transfused with erythrocyte suspension and freshly frozen plasma. TORCH IgM, Grubel-Widal and Wright tests of the case were negative. Ammonia, urine-blood aminoacid levels, Alpha-1 antitrypsin levels, tests for Gaucher disease, NiemannPick $A$ and $B$ enzyme levels were normal and no pathology was detected in the eye-bottom examination. Repeated bone marrow biopsy was evaluated as normocellular. However, acid was also found in the case that started jaundice, $T$ bilirubin 5 $\mathrm{mg} / \mathrm{dL}$ and D bilirubin $4 \mathrm{mg} / \mathrm{dL}$. In the case of hypoalbuminemia and international normalized ratio: 2, hemorrhagic papular lesions of various sizes were observed in both palms and on the back of the hand while preparing for liver transplantation. The 
case was diagnosed as Langerhans cell histiocytosis after the widespread CD1 a antigen positive histiocytes were observed in histopathological examination of skin biopsy material from lesions. He was referred to an oncology clinic.

\section{Case 9}

The seven-month-old girl was brought with a complaint of rash on the body, which has been for two months. She has been using antifungal, antibiotic and corticosteroid creams with her diaper rash due to rash, itching and crusting, which has been continuing for two months in her body, especially in the folds of the body to be more than two months, continuing since the last four weeks also increasing the redness. It was learned that he was referred to the gastroenterology outpatient clinic with a diagnosis of allergy. On physical examination, weight: $7 \mathrm{~kg}$ (25 pairs), height: $67 \mathrm{~cm}$ (50 pairs) and general condition was moderate. In addition to the common erythematous, patched papular-looking lesions on the neck, trunk, the structure of the nails was disrupted and there were hemorrhagic lesions in some erythematous areas. Respiratory and cardiovascular system examinations were normal. Liver was $3 \mathrm{~cm}$ in the midclavicular line, and her spleen was palpated by $2 \mathrm{~cm}$. Laboratory investigations were Hgb: $10.1 \mathrm{~g} / \mathrm{dL}$, Hct: $31 \%$, white blood: $4420 / \mathrm{mm}^{3}$, platelet: $207,000 / \mathrm{mm}^{3}$. The diagnosis of langerhans cell histiocytosis was made in the histopathological examination of the skin punch biopsy material taken from the patient with normal liver, kidney functions and serum electrolytes. Verbal consent was obtained from all cases.

\section{DISCUSSION}

Malignant diseases are not uncommon in childhood and adolescence and can always appear with different clinical signs and symptoms. Tumors that occupy the abdomen in childhood may appear with different clinical findings in different localizations. Most tumors that show intraabdominal location give symptoms such as abdominal pain, bloating, nausea, vomiting, constipation or diarrhea. However, most abdominal masses in children are asymptomatic and often noticed by family or doctor during routine examination. Sometimes the cases are taken to the doctor with complaints such as pain, vomiting and constipation due to the mass (2). Burkitt lymphoma is a fast-growing malignant tumor. In non-Hodgkin lymphoma, which is the nonendemic form that causes abdominal mass, clinical findings vary depending on the localization of the tumor. In 35\% of the patients, the tumor is localized in the abdominal region. It may originate from all lymphoid tissue in the intestinal wall, including the abdominal lymph nodes as well as the ileocecal region, the appendage and the ascending colon (5-7). Our three cases were brought in with abdominal bloating and abdominal pain. In one of the cases, a mass was detected in the colon, while the other two cases, were diagnosed with Burkitt lymphoma. Neuroblastoma is the most common extracranial solid tumor seen in childhood and accounts for $7 \%$ of childhood tumors (8). Since neuroblastoma can develop from any part of the sympathetic nerve chain, the location and clinic of the tumor are very variable and vary by age. Neuroblastoma cases usually do not have any complaints. Although the tumor is mostly found by chance during the examinations, 65\% are located in the abdomen $(9,10)$. Increased urine catecholamine metabolites (VMA, HVA) are very important in the diagnosis of neuroblastoma. Two of our cases (patients 4 and 5) were brought with the complaint of bloating in the abdomen, and a diagnosis of neuroblastoma was made as a result of the examinations. Brain tumors are the most common solid tumor seen in childhood. It constitutes $20 \%$ of cancers seen in children. It is the second most common malignant disease under the age of 15 after leukemias. Brain tumors are clinically grouped according to infratentorial and supratentorial localization. Medulloblastoma, which is one of the infratentorial tumors and located in the posterior fossa, is the most common brain tumor in the child age group (25\%). It accounts for $30-40 \%$ of all posterior fossa tumors. This tumor is seen more in boys than in girls, but peaks at ages 5-9 $(11,12)$. One of our cases was two years old, the other was 8 years old, and both were admitted with morning vomiting. After the examinations, they were diagnosed with posterior fossa tumor, which is common in this age group as stated in the literature. Langerhans cell histiocytosis is a rare disease characterized by abnormal histiocyte proliferation, whose etiology has not yet been fully elucidated. This disease, which has an annual incidence of 3-4 per million, can occur at any age in childhood. Itchy erythematous papules, vesiculopustules, petechiae, erosion and ulcerations are seen in the groin. There may be atrophy in the inguinal folds. Systemically, anemia, diarrhea, hepatosplenomegaly, bone involvement and lymphoadenopathies can be detected. The definitive diagnosis is made by showing the CD1a surface antigen immunohistochemically in the biopsy samples taken from skin or bone lesions or by showing the langerhans cells under the electron microscope. Chemotherapy (vinblastin and etoposide), local radiotherapy or isolated curettage can be applied in treatment $(3,4)$. In one of our two cases, the first finding was rash on the body, but in the other, the first finding was organomegaly. However, hemorrhagic papular lesions of various sizes were observed in both palms. LCH was diagnosed by histopathological examination of skin biopsy of both cases. Malignant diseases should be kept in mind in cases presenting with hepatosplenomegaly, persistent fever and pallor as in these cases presenting with various gastrointestinal findings.

As a result, as with any disease, knowledge, awareness, correct synthesis and appropriate approach are required in the diagnosis of neoplastic diseases. Therefore, the complaints of the gastrointestinal tract are primarily a symptom of a gastroenterological disease, but may also concern other clinical departments, especially oncology. Patients presenting with these non-specific complaints, which are the precursors of many diseases such as vomiting, dermatological findings, abdominal bloating, should be directed to the minor clinics after being evaluated in more detail by general pediatricians.

Informed Consent: Verbal consent was obtained from all cases.

Peer-review: Externally peer-reviewed. 
Author Contributions: Concept - N.U.; Design - N.U.; Supervision - Z.Y.Y.; Resources - R.G.; Materials - B.G.; Data Collection and/or Processing N.U., Analysis and/or Interpretation - N.U.; Literature Search - R.G.; Writing Manuscript - N.U.; Critical Review - N.U.

Conflict of Interest: The authors have no conflict of interest to declare.

Financial Disclosure: The authors declared that this study has received no financial support.

\section{REFERENCES}

1. Yang DM, Jung DH, Kim H, Kang JH, Kim JH, et al. Retroperitoneal cystic masses: CT, Clinical, and pathologic findigs and literature review. Radiographics 2004;24:1353-65.

2. Golden $\mathrm{CB}$, Feusner JH. Malignant abdominal masses in children: quick guide to evaluation and diagnosis. Pediatr Clin N Am 2002;49:1369-92.

3. Shin HT. Diaper dermatitis that does not quit. Dermatol Ther 2005:18:12435.

4. Chow TW, Leung WK, Cheng FWT, Kumta SM, Chu WCW, Lee V, et al. Late outcomes in children with Langerhans cell histiocytosis. Arch Dis Child 2017;102:830-5
5. Grajo JR, Kayton ML, Steffensen TS, Dragicevic N, Guidi CB. Presentation of ileal Burkitt lymphoma in children. J Radiol Case Rep 2012;6:27-38.

6. WHO Press, Swerdlow SH, Campo E, Harris NL, et al. WHO Classification of Tumours of Haematopoietic and Lymphoid Tissues. 2008;439

7. Bonnet C, Janssens A, Wu KL, Schroyens W, Hende WV, Heimann P, et al. BHS guidelines for the treatment of Burkitt's lymphoma. Belg J Hematol 2015;6:61-9.

8. Maris JM. Recent advances in neuroblastoma. N Engl J Med 2010;10:220211 .

9. London WB, Castleberry RP, Matthay KK, Look AT, Seeger RC, Shimada $H$. Evidence for an age cutoff greater than 365 days for neuroblastoma risk group stratification in the Children's Oncology Group. J Clin Oncol 2005;23:6459-65.

10. Bagatell R, Cohn SL. Genetic discoveries and treatment advances in neuroblastoma. Curr Opin Pediatr 2016;28:19-25.

11. Biegel JA. Genetics of pediatric central nervous system tumors. J Pediatr Hematol Oncol 1997;19:492-501.

12. Tortori-Donati P, Fondelli MP, Carini S, Cama A, Garre ML, Salomone G. Tumori neuroectodermici primitivi (PNETs) emedulloblastoma (PNETfossa Posteriore). Rivasta di Neuroradiologia 1992;5(Suppl 4):15-31. 